\title{
An Efficient CNC Programming Approach Based on Group Technology
}

\author{
Manocher Djassemi, Dept. of Industrial and Engineering Technology, Murray State University, \\ Murray, Kentucky, USA
}

\begin{abstract}
Many studies and reports support the significant impact of the application of group technology on various aspects of product design and manufacturing. The fact that group technology is the common solution to similar problems is the main source of such impact. In this paper, one of the less frequently utilized features of CNC technology known as parametric part programming is used to implement the common solution feature of group technology in processing a set of similar parts. Using three part families, the advantages of blending the concept of group technology and parametric programming for CNC machining operations are illustrated. The efficiency improvement due to the use of parametric programming in terms of number of setups and size of program is discussed.
\end{abstract}

Keywords: Group Technology, Computer Numerical Control, Parametric Part Programming

\section{Introduction}

Group Technology (GT) is a broad concept that uses common attributes to reduce redundant work in design and manufacturing and results in shorter product development and production time. This GT feature-shorter product development and production time-provides a significant advantage for manufacturers by enabling them to respond faster to market demand/changes and run production more economically in today's highly competitive manufacturing environment.

A significant amount of research and case studies in group technology shows that GT improves productivity in one or more aspects. ${ }^{1,2}$ The application of GT covers areas as diverse as design, process planning, tooling, scheduling, part programming, and material handling. In all cases, GT is used to find a common solution to a set of similar problems, that is, designing similar products or processing similar parts. Likewise, GT is used to classify part designs, allowing the efficient grouping of similar designs that can be manufactured on the same machine or machine cell. First, the approach avoids duplication of data in a database; and second, it results in significant reduc- tion in both number and variety of $C A D$ files, process plans, and NC part programs. Many companies in the US and Europe have adopted GT for standardization of design and production techniques. ${ }^{3}$

This study is focused on the implementation of the GT concept to a specific aspect of computer-aided manufacturing, that is, numerical control (NC) programming of machining and turning centers. The common solution for similar problems (CSSP) feature of GT and the parametric programming capability of computer numerical control (CNC) machines will be used to develop a single NC program for each part family. For CNC machine users, the combination of CSSP and parametric programming approaches is expected to create the opportunity to generate $\mathrm{NC}$ codes and operate $\mathrm{CNC}$ machines with greater efficiency. CNC machining or turning centers lend themselves to the CSSP concept in two ways: common tooling and common programming for a family of parts. When a family of parts is processed on these machines, tool indexing and loading/unloading are performed less frequently because most parts can be machined by a set of common tools. Similarly, the parametric programming feature of modern $\mathrm{CNC}$ machines allows a common program to be used for machining a number of similar parts.

Considering the potential benefits of such an application for group technology and CNC machine users, a study to link the parametric programming technique to GT system is appropriate. Using three examples, the efficiency improvement due to the joint application of the two technologies is discussed in the following sections.

\section{Parametric Part Programming}

Traditionally, separate part programs are written for individual parts within a part family; then the programs are loaded to the machine controller one by one. 
Most CNC machines have a special feature known as parametric programming, also referred to as macro, ${ }^{4}$ in which a part program can be written using variables and parametric expressions to represent the machine axis position $(x, y, z, a$, etc.), feed, and speed functions. ${ }^{5}$ Similar to computer programming languages such as Pascal or $\mathrm{C}$, computer-related features such as variables, arithmetic, logic statements, and looping can be implemented in a parametric program. This programming feature allows the user to load a single part program for a family of parts to the $\mathrm{CNC}$ controller. The part program is then called up for machining a similar part or similar feature on different parts. The process involves a simple entry of parameter values into the machine controller. For example, several cylindrical parts may have two common parameters, such as diameter and overall length. A single parametric part program can be called up from a main program for machining such a group of similar parts. Upon loading the main program, the values of the two parameters are entered; then these values are transferred to parametric subprograms. This approach could minimize the number of program changeovers, reduce the redundant codes in the part program, and shorten the length of the program.

\section{Methodology}

In this study, three part families are considered to investigate the effects of blending CSSP and parametric programming in improving the efficiency of $\mathrm{CNC}$ operations. The efficiency improvement is determined based on two factors: (a) number of program changeovers and (b) number of $\mathrm{NC}$ files and size of part program. As the number of part types within a part family increases, the number of program changeovers or setups is expected to increase. The number of NC files and the size of the part program can have a significant effect on file management and memory space when the number of part types within a part family is relatively high. Based on the aforementioned factors, an efficiency improvement (EI) measure is defined as follows:

$$
\mathrm{EI}=\frac{n-1}{n} * W+\frac{\left(\sum_{i}^{n} N_{i} / n\right)-P}{\left(\sum_{i}^{n} N_{i} / n\right)} *(1-W)
$$

where $n$ is the part family size

$N_{i}$ is the number of NC instructions (lines) in the conventional NC program for a part type $i$ in the family

$P$ is the number of NC instructions (lines) in the parametric program for the same part family

$W$ is the weight factor

The methodology consists of the following steps:

Step 1. Develop CAD files for the three part families.

Step 2. Generate NC codes using CAD/CAM software $^{6}$ for the parts' CAD files.

Step 3. Write a single parametric program for each part family. ${ }^{7}$

Step 4. Compare the two types of part programs developed in steps 2 and 3 using the EI measure.

The weight factor, $W$, is empirically determined using a Bridgeport $\mathrm{CNC}$ mill and a PC. It was observed that the ratio between the times to change programs, including clearing the control memory, and locating a program to program downloading time from a $\mathrm{PC}$ to $\mathrm{CNC}$ is roughly $4: 1(W=80 \%)$. This indicates that for the cases studied here, the effect of program length on EI is not as significant as the effect of machine stoppage for program changing (see Table 1).

\section{Analysis of Results}

Part family I consisted of five parts $(n=5)$, as illustrated in Figure 1. A single parametric part program for machining this part family is shown in the Appendix.

The numbers of instructions in conventional NC programs for individual part types were $66,37,132$, 104 , and 132 . The number of executable NC instructions in the corresponding parametric program was 45 lines. The overall EI due to application of para-

Table I

Program Changeover and Downloading Times (seconds)

\begin{tabular}{llll}
\hline & \multicolumn{3}{c}{ Part Family } \\
& I & II & III \\
\hline Changeover time & 40 & 35 & 27 \\
Downloading time & 11 & 8 & 8
\end{tabular}




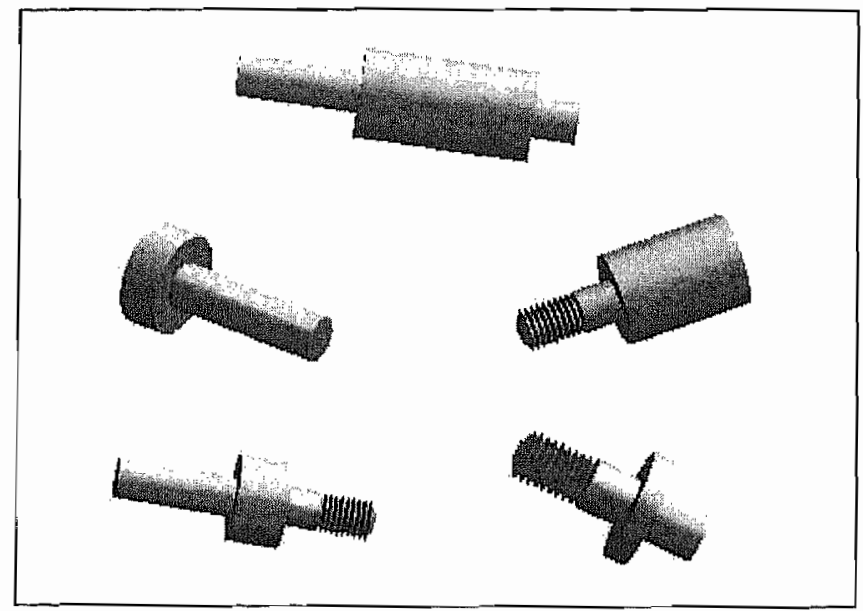

Figure 1

Part Family I

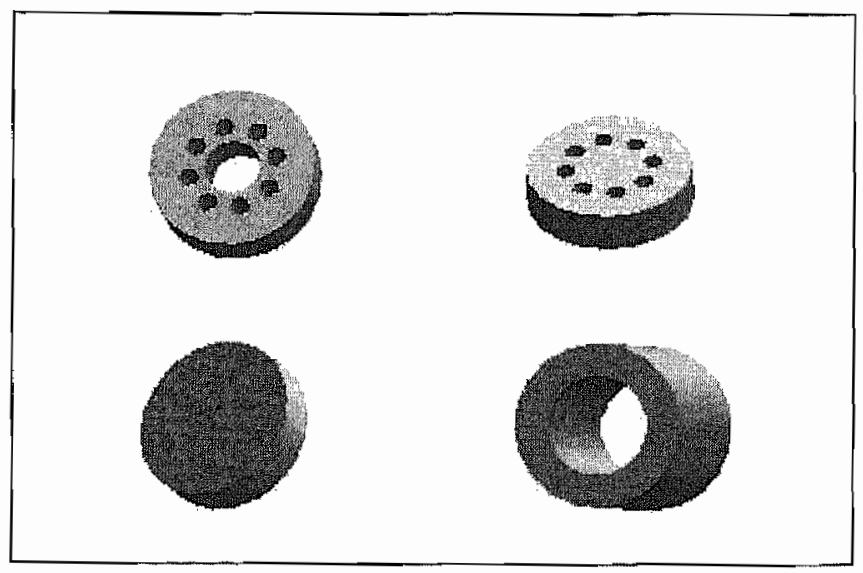

Figure 2

Part Family II

metric programming was $74 \%$. However, if the numbet of part types in the part family grows and the new part members are different from the old ones only in terms of values of specified parameters in the program, such as diameter and overall length, then EI yields greater efficiency in programming the $\mathrm{CNC}$ machine. For example, for 15 part types $(n=15)$ the EI increases from $75 \%$ to $85 \%$.

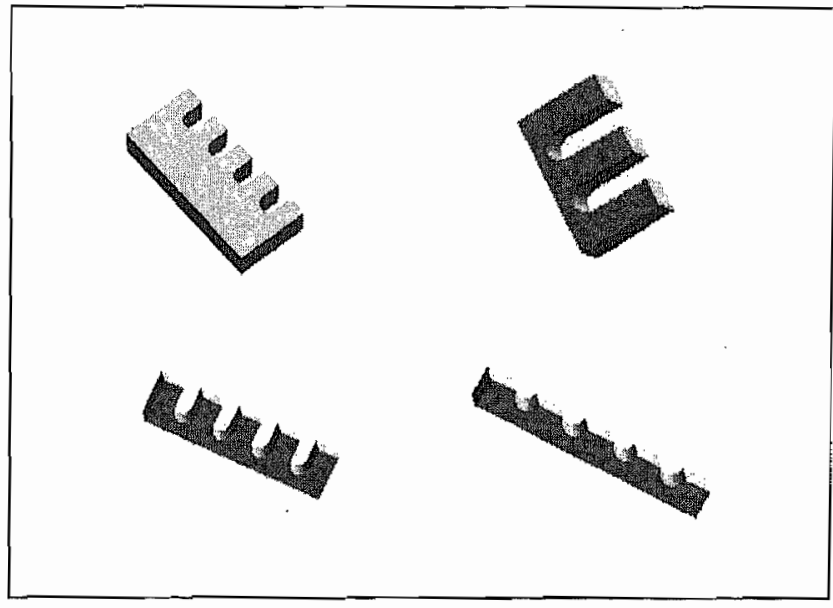

Figure 3

Part Family III

Part family II consisted of four parts (Figure 2). The number of NC instructions for individual part types were 27, 53, 8, and 34 lines for this group. The number of $\mathrm{NC}$ instructions in the corresponding parametric program was 25 lines (see the Appendix). The use of parametric programming resulted in a $64 \%$ improvement in programming efficiency. When a larger number of similar parts $(n=15)$ were included by changing the value of the parameters, including external radius, thickness, diameter of center pocket, and number of holes, then the EI improved from $64 \%$ to $78 \%$.

Part family III consisted of four parts (Figure 3). The number of NC instructions in the conventional part program remained at 53 for all part types. The number of $\mathrm{NC}$ instructions in the corresponding parametric program was 25 lines. The use of parametric programming resulted in a $64 \%$ improvement in programming efficiency for this part family. By changing the value of four parameters, including length, width, thickness, and number of slots, additional parts may be included in this group. Increasing the number of part types to 15 improved the EI from $64 \%$ to $85 \%$.

Table 2

Summary of Numerical Results

\begin{tabular}{|c|c|c|c|c|c|c|}
\hline $\begin{array}{c}\text { No. of } \\
\text { Part Program }\end{array}$ & $\begin{array}{l}\text { No. of } \\
\text { Part } \\
\text { Types } \\
(n)\end{array}$ & $\begin{array}{c}\text { No. of } \\
\text { Part Program }\end{array}$ & $\begin{array}{l}\text { Avg. No. of } \\
\text { Instruction } \\
\text { Lines per } \\
\text { Part Family }\end{array}$ & $\begin{array}{l}\text { No. of } \\
\text { Instruction in } \\
\text { Parametric } \\
\text { Program }\end{array}$ & $\begin{array}{c}\text { Efficiency } \\
\text { Improvement } \\
(\mathrm{EI}) \\
n=5\end{array}$ & $\begin{array}{c}\text { Efficiency } \\
\text { Improvement } \\
\text { (EI) } \\
n=15^{*}\end{array}$ \\
\hline$I$ & 5 & 5 & 94 & 45 & $54 \%$ & $85 \%$ \\
\hline II & 4 & 4 & 30 & 25 & $25 \%$ & $78 \%$ \\
\hline III & 4 & 4 & 53 & 24 & $53 \%$ & $85 \%$ \\
\hline
\end{tabular}

*The number of part types in each family increased by 15 by changing the value of parameters. 
Table 2 summarizes the comparison results of the two methods of NC programming applied to the three part families under study.

\section{Conclusion}

The results of this study support the findings of many other reports and studies regarding the effects of adopting group technology in improving the efficiency of manufacturing operations. The parametric programming approach was used as a means to implement the common solution for similar problems (CSSP) feature of group technology in CNC machining operations where there are some similarities among the parts. The numerical results showed an improvement in efficiency of NC programming after applying the parametric programming approach to three part families. Such improvement is more significant when the number of part types 'within a part family is relatively high. It is recommended that GT users adopt parametric programming for large part families or whenever there is a growing trend in the size of the part family to minimize program changeovers and the number of similar NC files. A threshold value for part family size can be determined based on a cost-benefit analysis considering the time for program changeover and the time to write the NC program in conventional and parametric fashions.

In today's competitive economy, manufacturing companies have no alternative other than taking advantage of the new technologies in improving the efficiency of their operation. Parametric programming as the best-kept secret of modern $\mathrm{CNC}$ machines ${ }^{5}$ is already at the machine tool users' disposal. Surveys on successful applications of parametric part programming in group technology facilities would be an appropriate extension to this study.

\section{Appendix}

\section{Parametric Part Programs}

0001

G20

G0 T0101

G97 S1500 M3

G96 S1200

(CHECK RIGHT SHOULDER)
(P10 EXTERNAL DIAMETER OF BAR)

(P11 LENGTH OF RIGHT SHOULDER)

(P13 SHOULDER DIAMETER)

IF P11 $=0$ GOTO N3

G0 X[P10]+.1 Z.1 (MACHINING RIGHT SHOULDER)

G71 P1 Q2 I0 K0 R0 D.05

N1

G0 X [P13]

G1 Z0

$\mathrm{Z}[-\mathrm{P} 11]$

$\mathrm{X}[\mathrm{P} 10]$

N2

()

N3 (CHECK THE THREAD)

(P12 \# OF PASSES)

(P13 MAJOR DIAMETER)

(P14 \# OF THREADS/INCH)

(P15 LENGTH OF THREAD)

IF P12=0 GOTO N4

G0 T0202 (MACHINING THE UNC THREAD, $\mathrm{H}=.6495 \mathrm{P})$

G0 Z.5

$\mathrm{P} 6=0$

WHILE P6 LT [P12]

$\mathrm{P} 6=\mathrm{P} 6+1$

G0 X[P13-[P6*[[.6495/P14]/P12]]]

G32 Z[-P15] F.005

G0 X[P13]

G0 Z.1

WEND

N4 (CHECK LEFT SHOULDER)

(P16 DISTANCE FROM RIGHT FACE TO)

(SHOULDER)

(P17 OVERALL LENGTH OF PART)

(P18 DIAMETER OF LEFT SHOULDER)

N3 IF P16=P17 GOTO N10

G0 T0303 (MACHINING LEFT SHOULDER)

G0 X[P10]

$\mathrm{Z}[-\mathrm{P} 16]$

G71 P5 Q6 I0 K0 R0 D.05

N5

G0 X[P18]

G1 Z[-P16]

$\mathrm{Z}[-\mathrm{P} 17]$

$\mathrm{X}[\mathrm{P} 18]$

N6

$\mathrm{N} 10$

G0 T0404 (CUTOFF THE PART)

G0 X[P10]+.1 


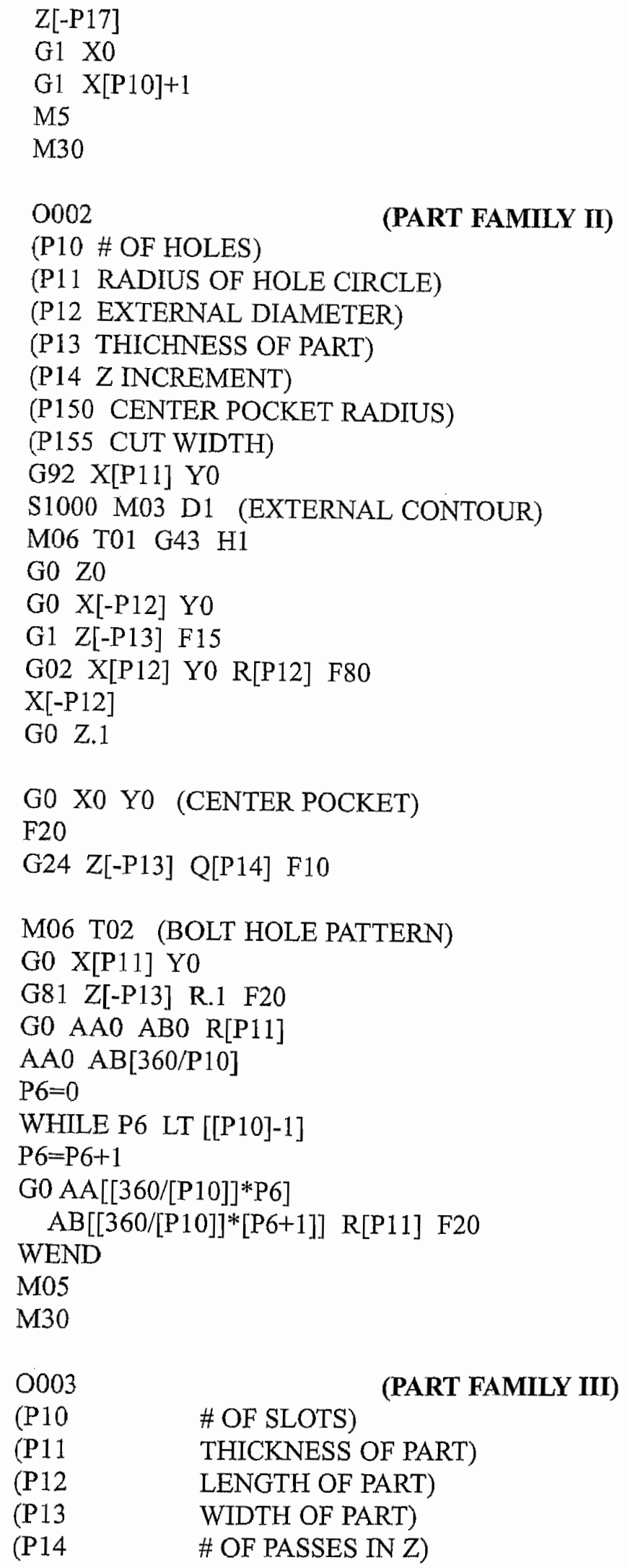

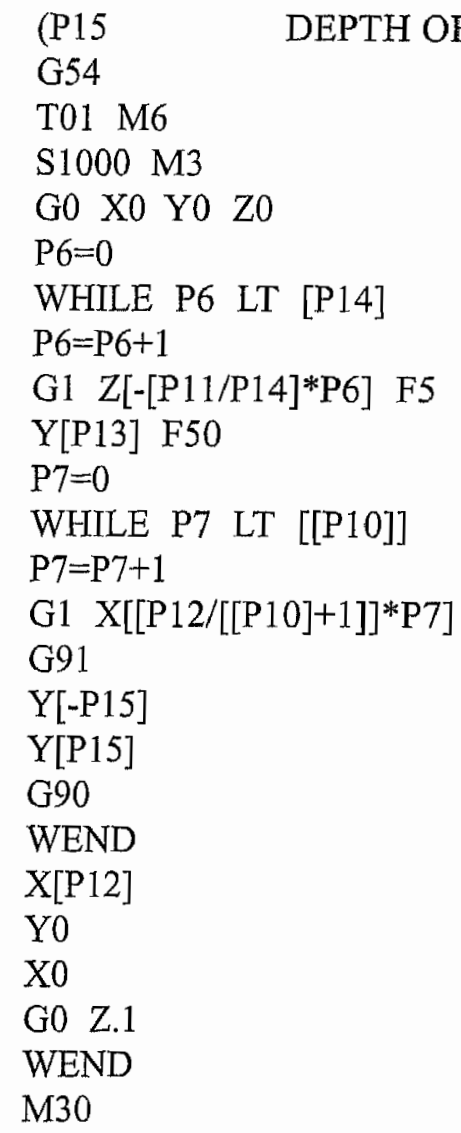

\section{References:}

1. J.L. Burbidge, "Change to Group Technology: Process Organization is Obsolete," Int'l Journal of Production Research (v30, 1992), pp1209-1220.

2. A.M. Kriegler, "GT Improves Flow, Cuts Costs," American Machinist (Mar. 1984).

3. C. Mosier and L. Taube, "The Facets of Group Technology and Their Impacts on Implementation-A State-of-the-Art Survey," OMEGA, Int' Journal of Mgmt. Science (v13, n5, 1985), pp381-391.

4. P.J. Amic, Computer Numerical Control Programming (Englewood Cliffs: Prentice-Hall, 1997), p226.

5. M. Lynch, Managing Computer Numerical Control Operations: How to Get the Most Out of Your. CNC Machine Tools (Dearborn, MI: Society of Mfg. Engineers, 1995).

6. CNC Software, Inc., "MasterCAM Mill Application Manual" (Holland, CT: 1993).

7. Miltronics Mfg. Co., "Centurion V Operation Manual, Version 1.3" (Chanlassen, MN: Dec. 1990).

\section{Author's Biography}

Manocher Djassemi received a BSIE from the University of Science and Technology in Tehran, Iran, and an MS and PhD from the University of Wisconsin-Milwaukee. He is an assistant professor in the Dept, of Industrial and Engineering Technology at Murray State University. He has also tanght in the industrial studies department at the University of WisconsinPlatteville. Dr. Djassemi has five years of industrial experience and is a certified manufacturing engineer. His primary areas of teaching and research are conventional and CNC machine tools, robotics, CAD/CAM, group technology, and cellular manufacturing. 